\title{
The Effect of Bi-Cortical Screw Fixation for Subsidence and Cervical Alignment in Patients Undergoing Single-Level Anterior Cervical Discectomy and Fusion
}

\author{
Woong Han, Byoung Gwan Moon, Deok Ryeong Kim, Jae Hoon Kim, Hee In Kang, Joo Seung Kim \\ Department of Neurosurgery, Nowon Eulji Medical Center, Eulji University School of Medicine, Seoul, Republic of Korea
}

Corresponding author:

Woong Han

Department of Neurosurgery,

Nowon Eulji Medical Center, Eulji

University School of Medicine, 68,

Hangeulbiseok-ro, Nowon-gu, Seoul

01830, Republic of Korea

Tel: $+82-2-970-8312$

Fax: $+82-2-970-8313$

E-mail: hanw881210@naver.com

Received: August 5, 2019

Revised: September 17, 2019

Accepted: September 19, 2019

\begin{abstract}
Objective: Anterior cervical discectomy and fusion (ACDF) is a treatment for cervical degenerative disease. However, there are few in vivo or long-term data sets including complete graft consolidation. This study aimed to verify the validity of bi-cortical screw fixation in patients undergoing ACDF. Methods: We enrolled 133 patients who underwent ACDF between February 2002 and March 2017. Patients were divided into the mono-cortical fixation group (group A) and bi-cortical fixation group (group B). Consecutive cervical radiography was performed. The end point of data collection was completion of fusion. We evaluated graft subsidence, the global cenvical angle (C2-C7 Cobb's angle), and segmental angle (SA; index level Cobb's angle). Results: There were no significant differences or surgical level between groups $A$ and $B$ (graft type $p=$ 0.292 , surgical level $p=0.065$ ). However, types of plate were statistically different (plate type $p$-value $=0.011$ ), and the difference in subsidence between groups $A$ and $B$ was significant (group A, 3.946 $\pm 2.43 \mathrm{~mm}$; group $\mathrm{B}, 2.369 \pm 1.96 \mathrm{~mm}, \mathrm{p}<0.001$ ). In the logistic regression, bi-cortical screw fixation was found to be the most important factor contributing to subsidence reduction ( $\beta$-coefficient, 1.002; odds ratio $=2.725 ; p=0.012$ ). There was a significant difference in the SA when fusion was achieved (group $A, 2.14 \pm 5.05^{\circ}$; group $B, 4.84 \pm 4.83^{\circ} ; p=0.002$ ). The change in the $S A(\triangle S A)$ was significantly different between group $A$ and group $B$ (group $A$, $\triangle S A-4.42 \pm 4.04^{\circ}$; group $B, \triangle S A-1.15 \pm 3.64^{\circ} ; p=0.001$ ). Conclusion: Bi-cortical screw fixation in ACDF led to reduced graft subsidence and a less kyphotic SA change.
\end{abstract}

Key Words: Bone screws; Cervical vertebrae; Diskectomy; Spinal fusion

\section{INTRODUCTION}

Anterior cervical discectomy and fusion (ACDF), which was first introduced as a surgical procedure to treat cervical degenerative disease ${ }^{24}$, has been used as an effective surgical treatment since 1958. The main purpose of this surgery is to decompress the nervous system while maintaining the physiological disc height and achieving fusion to attain cervical stability ${ }^{11}$. Advancements in instrumentation and interspace grafting have resulted in the improved success and safety of this procedure ${ }^{23)}$. However, although the surgical procedure has evolved, there are several complications associated with ACDF such as pseudoarthrosis $^{6}$, implant extrusion ${ }^{23)}$, and subsidence ${ }^{14)}$. In particular, graft subsidence has been reported to occur before segmental kyphosis and acceleration of adjacent segment disease ${ }^{1,7,22,26)}$. Thus, this phenomenon has become a major issue for surgeons to overcome. The known risk factors for subsidence are age, body mass index (BMI), smoking history, low bone mineral density $(\mathrm{BMD})^{2)}$, end plate preparation ${ }^{15)}$, cage type ${ }^{1,7,22,26)}$, and location $^{21)}$. Furthermore, in a recent clinical study, cervical alignment $^{13,14)}$ and even a small degree of segmental instability ${ }^{10,12,19,25)}$ have been suggested as risk factors for subsidence.

Although, after introducing the self-locking plate system in ACDF, complications such as screw loosening, screw pullout or plate loosening have been markedly diminished ${ }^{16)}$. But, however, according to study by Ning et al. ${ }^{17)}, 4.9 \%$ of patients still undergoes the complications such as subsidence, screw loosening or plate loosening after ACDF. Those phenomenon could contribute severe complications such as severe subsidence or esophageal injury. To overcome those complications, we have been tried to find the way to introduce more holding strength in self-locking plate system.

In our clinic, we have struggled to achieve a good outcome using several types of plates and interspacing devices, and evidence to determine whether the surgeon should place the screw bi-cortically or mono-cortically is scarce. A previous study reported that bi-cortically fixed screws resulted in additional stability in anterior cervical plating ${ }^{3}$. Another study suggested that bi-cortically fixed screws improved the holding strength ${ }^{20)}$. 
According to another study by Conrad et al. ${ }^{5)}$, the length of screw insertion is related to stronger pull out force. Researchers was inspirited by those studies that bi-cortical screw fixation provide additional holding strength in ACDF.

In the present study, we hypothesized that bi-cortically fixed anterior cervical screws would increase the holding strength until fusion is achieved compared with mono-cortically fixed screws, resulting in a more favorable environment and less subsidence. To test this hypothesis, we performed a retrospective study to assess whether bi-cortical screw fixation was more favorable in terms of subsidence and cervical alignment in patients undergoing single-level ACDF.

\section{MATERIALS AND METHODS}

\section{Patient Populations and Inclusion Criteria}

A total of 133 patients with herniated cervical discs were recruited between February 1, 2002 and March 31, 2017. Patients with cervical stenosis or ossification of the posterior longitudinal ligament were excluded. Patients with cervical trauma, fracture, incomplete cord injury, or complete cord injury were also excluded. This retrospective study was conducted at a single neurosurgery center and by 1 surgeon. Patients were not excluded on the basis of age, sex, compensation claims, smoking history, osteoporosis, BMI, or other medical comorbidities. Researchers categorized the patients by factors that influence graft subsidence. The considered surgical factors were whether the screws were fixed mono-cortically or bi-cortically, whether an allograft (human humerus allograft) or autograft (iliac bone graft) was used, and the type of plate fixation system. The demographic data of the anterior cervical discectomy cases are shown in the Table 1 .

\section{Surgical Procedure}

All patients underwent surgery by a single surgeon using the same surgical technique. The anterior approach was adopted by standard anterior cervical exposure through the right side. The affected discs were removed with pituitary forceps and curettes. The anterior edge of the upper vertebra in the interbody space was removed. The posterior edges of the upper and lower vertebra and uncinated process were removed by high-speed drilling with a $2.3 \mathrm{~mm}$ fluted Matchstick burr; bone dust and bony fragments for graft materials was collected. Complete uncotomy and partial superior pediculotomy were performed in cases of radiculopathy to ensure foraminal decompression. Discectomy was performed by confirming the anterior aspect of the dura matter in the case of myelopathy. Both the upper and lower endplates were prepared by completely removing the cartilaginous endplate. The end point of the endplate preparation was petechial oozing from the subchondral bone by high speed drilling with a $3 \mathrm{~mm}$ cylindrical carbide drum and sharp curettes. The interbody graft was introduced to fit snugly into the interbody space after removal of the intervertebral distractor. Graft fitting was optimal when the graft could be rotated and removed from the interspace easily without longitudinal motion of the graft. After insertion of the interbody graft, the plate and screw fixation system was applied. The point of screw entry was the midline of the screw hole on the distal half of the plate; controlled penetration of the posterior cortex could be achieved by setting the adjustable drill to stop at the appropriate depth. The direction of the screw was medially convergent with caudal or cephalad away of graft for inducing compression force. Insertion angle of upper vertebral body screw was between 20 to 30 degrees caudally to the lower endplate of upper vertebrae body. Furthermore, lower vertebral body screws were inserted parallel to the lower endplate of the lower vertebral body.

\section{Bi-cortical Screw Insertion Technique and Inclusion Criteria}

Bi-cortical screw fixation is defined as penetration of the posterior cortex of the vertebra by the screw tip. And, inclusion criteria for bi-cortical screw fixation group was defined by the preoperation (Pre-OP) disc height. If patients had loss of disc height more than 25\% than adjacent disc height, they were decided to insert the screw bi-cortically. The optimal length of the bi-cortical screw should not be determined preoperatively by measuring the vertebral body using a Pre-OP computed tomography (CT) or magnetic resonance imaging. Instead, the length of the bi-cortical screw was determined intraoperatively. When insert the screw to the vertebra body, the length of the screw was defined as $1 \mathrm{~mm}$ plus anterior-posterior diameter of vertebra body by using depth gauge (Fig. 1).

\section{Radiologic Evaluation}

Consecutive plain lateral radiographs obtained before and after operation and at the follow-up (F/U) were used to measure parameter values. These measured values were manipulated

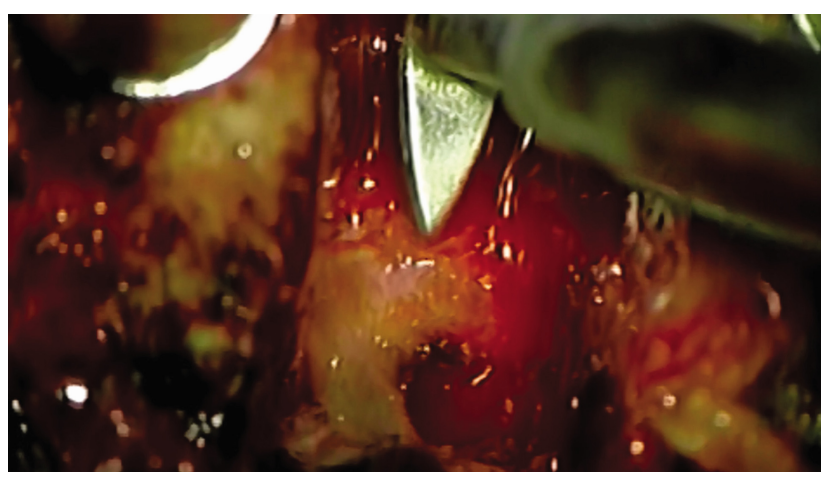

Fig. 1. Depth gauge measurement during surgery. 
to calculated values. The measured parameters were segmental height (SH), segmental angle (SA), global angle (GA), and C2 vertebra body height as a calibration value. SH was defined as the distance from the upper end plate of the superior vertebra to the lower end plate of the inferior vertebra. SA was defined as the Cobb angle between the affected segments. GA was defined as the Cobb angle between the C2 vertebra body and $\mathrm{C} 7$ vertebra body. C2 vertebral body height was defined as the distance from the top of the odontoid process to the lower endplate of the $\mathrm{C} 2$ vertebral body. Calculated values were derived from measured values, which included distraction, subsidence, SA change, and GA change. Distraction was defined as postoperation (Post-OP) SH minus Pre-OP SH (Distraction= Post-OP [OP] SH-Pre-OP SH). Subsidence was defined as PostOP SH minus F/U SH (Subsidence=Post-OP SH $-\mathrm{F} / \mathrm{U} \mathrm{SH}$ ). Change in the Post-OP SA was defined as the Post-OP SA minus Pre-OP SA( $\Delta$ Post-OP SA=Post-OP SA - Pre-OP SA). Change in the F/U SA was defined as the F/U SA minus Post-OP $\mathrm{SA}(\Delta \mathrm{F} / \mathrm{U} \mathrm{SA}=\mathrm{F} / \mathrm{U}$ SA - Post-OP SA). Change in the Post-OP GA was defined as the Post-OP GA minus Pre-OP GA ( $\triangle$ Post-OP GA=Post-OP GA - Pre-OP GA). Finally, change in the F/U GA was defined as the F/U GA minus Post-OP GA ( $\Delta \mathrm{F} / \mathrm{U}$ GA=F/U GA - Post-OP GA). To con firm bi-cortical screw fixation, we used Post-OP CT scanning and Post-OP plain cervical lateral films. Whether the screws fixed bi-cortically or mono-cortically was measured by Post-OP CT scan. If the tip of the screw was shown to penetrate through the posterior cortex upon CT scanning, patients were placed in the bi-cortical screw fixation group. In addition, the inclusion criteria of bi-cortical screw fixation group was confirmation of bi-cortical screw at both upper vertebra body and lower vertebra body at CT scan. And also, mono-cortical screw group was determined as confirmation of mono-cortical screw at both upper vertebra body and lower vertebra body. In cases of bi-cortical screws presenting only one vertebra body (Upper vertebra body or lower vertebra body) were excluded in this study (Fig. 2-4).

\section{Subsidence Group and Non-Subsidence Group}

In this study, subsidence was defined as $\mathrm{F} / \mathrm{U}$ SH minus Post$\mathrm{OP} \mathrm{SH}$. Although subsidence is a continuous variable, to carry out statistical analysis of non-continuous variable such as Kai square test. The variable should be divided into categorical data. Thus, the cut off value of subsidence group and non-subsidence group considered as major issue to researchers. According to meta-analysis carried out by Karikari et al. ${ }^{9}$, , some studies considered $2 \mathrm{~mm}$ of subsidence in ACDF as the subsidence group, whereas others considered $3 \mathrm{~mm}$ of subsidence in ACDF as the subsidence group. In this meta-analysis, ACDF cases by using anterior cervical plating system defined the subsidence group as $3 \mathrm{~mm}$ of subsidence. Furthermore, in our center, ACDF was carried out by using anterior cervical plate. Researchers therefore decided $3 \mathrm{~mm}$ of subsidence as to be the cut off value.

\section{Kyphotic Change Group and Lordotic Change Group}

Patients were subdivided into 2 groups following to the $\Delta \mathrm{F} / \mathrm{U} \mathrm{SA}(\Delta \mathrm{F} / \mathrm{U} \mathrm{SA}=\mathrm{F} / \mathrm{u} \mathrm{SA}$ - Post-OP SA). If the $\Delta \mathrm{F} / \mathrm{U}$ SA was more than 0 degree, they were considered as lordotic SA change group. And the other cases, $\Delta \mathrm{F} / \mathrm{U}$ SA less than 0 degree, they were considered as kyphotic SA change group. Furthermore, patients were divided in to subgroup by the following equation $\Delta \mathrm{F} / \mathrm{U}$ GA $(\Delta \mathrm{F} / \mathrm{U}$ GA $=\mathrm{F} / \mathrm{U}$ GA - Post-OP GA). If the patients indicated more than 0 degree in $\Delta \mathrm{F} / \mathrm{U} G$, they were assigned to the lordotic global angel change group; if the patient showed less than 0 degree in $\Delta \mathrm{F} / \mathrm{U}$ GA, they were assigned to

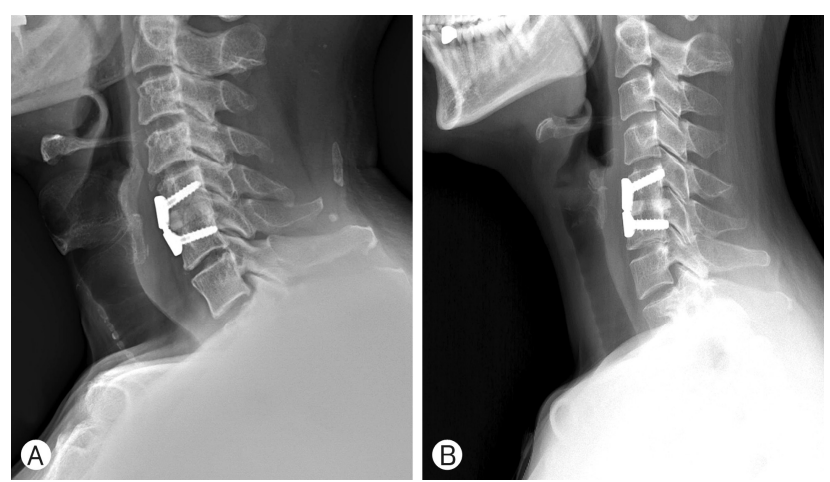

Fig. 2. Plain radiograph of mono-cortical fixation group (A) and bicortical fixation group (B).

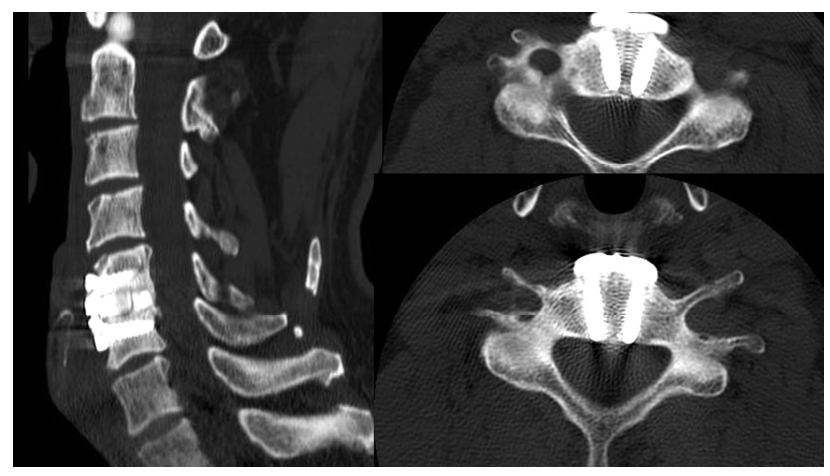

Fig. 3. Computed tomography images of mono-cortical fixation group.

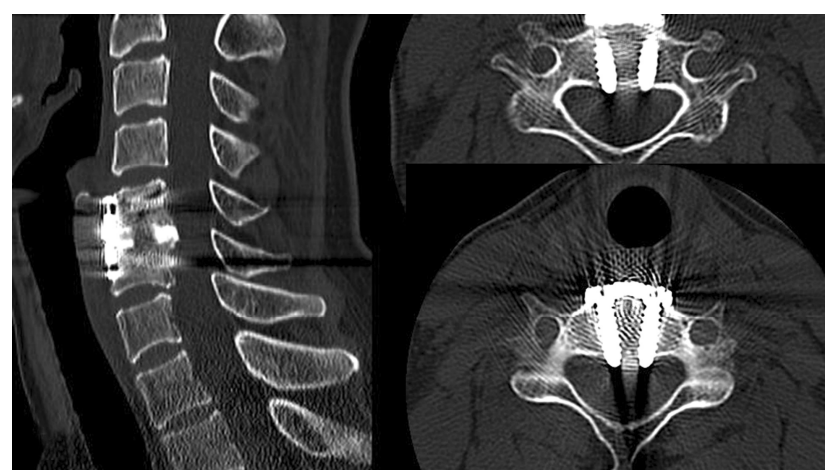

Fig. 4. Computed tomography images of bi-cortical fixation group. 
the kyphotic global angel change group.

\section{Statistical Analysis}

For demographic data, the $\chi^{2}$ test was used to confirm whether selection bias existed in each group. To confirm the difference between the bi-cortical screw group and mono-cortical group, an independent t-test was used. In addition, an independent t-test was conducted to assess for a difference between the graft usage groups. To confirm the difference between types of plate, a 1-way analysis of variance (ANOVA) was used. Possible surgical factors then underwent logistic regression analysis and patients were grouped according to the $\Delta \mathrm{F} / \mathrm{U}$ GA and $\Delta \mathrm{F} / \mathrm{U}$ SA. A negative value was considered as a kyphotic change and a positive value was considered as a lordotic change; patients were divided into 2 groups accordingly. Furthermore, patients who suffered from subsidence of $>3 \mathrm{~mm}$ were placed in the subsidence group, which was compared to a non-significant subsidence group. To confirm a correlation between the groups, we conducted a $\chi^{2}$ test. The p-values $<0.05$ were considered to be statistically significant. IBM SPSS 23.0 (IBM Corp., Armonk, NY, USA) was used to analyze all data.

\section{RESULTS}

\section{Demographic Data}

A total of 133 cases were included in this study; 64 cases comprised the mono-cortically placed screw group (group A) and 69 cases comprised the bi-cortically placed screw group (group B). In group A, 11 cases used an Atlantis cervical plate
(Medtronic-Sofamor Danek, Memphis, TN, USA), 25 cases used a Vectra-translation cervical plate (DePuy Synthes Inc., West Chester, PA, USA), and 28 cases used a Vectra-fixed cervical plate (DePuy Synthes Inc.). In group A, 53 cases used an allograft for surgery and 11 cases used an autograft. In group B, 24 cases used an Atlantis cervical plate, 30 cases used a Vectra-t plate, and 15 cases used a Vectra-f cervical plate. In group B, 52 cases used an allograft and 17 cases used an autograft. The $\chi^{2}$ test revealed no significant difference in types of graft. However, the types of plate system was indicated by the significant difference found in $\chi^{2}$ test (Table 1 ).

\section{Subsidence and Screw Fixation Type}

The mean $\mathrm{F} / \mathrm{U}$ SH and distraction did not significantly differ between the mono-cortical fixation group and bi-cortical fixation group. However, Pre-OP SH, Post-OP SH indicated a significant difference between the groups. The subsidence was found to be significantly different between the 2 groups (group A, $3.946 \pm 2.43 \mathrm{~mm}$; group B, 2.369 $\pm 1.96 \mathrm{~mm}$; $<<0.001$ ).

The patients were then sub-divided into 2 groups according to the degree of subsidence. In the mono-cortical screw fixation and bi-cortical screw fixation group, 38 and 22 cases had significant subsidence, which was significantly different between the 2 groups $(\mathrm{p}=0.001)$ (Tables 2, 3).

\section{Subsidence and Oher Factors}

We measured the difference in the subsidence according to graft type and plate type. The mean subsidence was significantly different between the autograft and allograft groups $(1.022 \pm 1.28 \mathrm{~mm}$ and vs. 3.689 $\pm 2.22 \mathrm{~mm}$ and $0.08 \pm 0.05 ; \mathrm{p}=$

Table 1. Demographic data of single-level anterior cervical discectomy and fusion

\begin{tabular}{|c|c|c|c|}
\hline & Mono-cortical screw fixation $(n=64)$ & Bi-cortical screw fixation $(n=69)$ & p-value \\
\hline \multicolumn{4}{|c|}{ 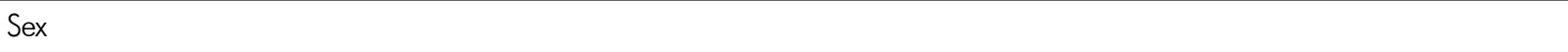 } \\
\hline Male & 39 & 32 & \\
\hline Female & 25 & 37 & \\
\hline Level & & & 0.065 \\
\hline C4-5 & 10 & 11 & \\
\hline C5-6 & 31 & 42 & \\
\hline C6-7 & 23 & 16 & \\
\hline Plate type ${ }^{*}$ & & & $0.011^{*}$ \\
\hline Atlantis $^{+}$ & 11 & 24 & \\
\hline 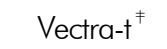 & 25 & 30 & \\
\hline Vectra-f $f^{\S}$ & 28 & 15 & \\
\hline Graft type & & & 0.292 \\
\hline Allograft & 53 & 52 & \\
\hline Autograft & 11 & 17 & \\
\hline
\end{tabular}

${ }^{*}$ Indicates statistical significance. ${ }^{+}$Atlantis cervical plate system. ${ }^{\ddagger}$ Vectra-translation cervical plate system. ${ }^{\S}$ Vectra-fixed cervical plate system. 
0.003). According to plate type, a 1-way ANOVA revealed that subsidence was also significantly different between the groups $(\mathrm{p}<0.001)$. The mean subsidence values were $1.094 \pm 1.28 \mathrm{~mm}$, $3.472 \pm 1.95 \mathrm{~mm}$, and $4.342 \pm 2.22 \mathrm{~mm}$ in the Atlantis, Vectra-t, and Vectra-f group, respectively. Post-hoc analysis showed that the Atlantis group and Vectra group were significantly different $(\mathrm{p}<0.05)$ (Table 4).

We then analyzed these factors combined with screw positioning using logistic regression. Bi-cortical screw fixation $\beta$-coefficient was 1.002 and $p=0.012$, usage of autograft $\beta$-coefficient was 0.819 and $\mathrm{p}=0.518$, and Atlantis plate system beta-coefficient was 1.554 and $\mathrm{p}=0.165$ (Table 5).

\section{Cenvical Alignment and Screw Fixation Type}

Regarding groups A and B, we observed a significant betweengroup difference in the $\mathrm{F} / \mathrm{U} \mathrm{SA}$ (group A, $2.14 \pm 5.05^{\circ}$; group $\mathrm{B}$, $4.84 \pm 4.83^{\circ} ; \mathrm{p}<0.05$ ), the $\Delta \mathrm{F} / \mathrm{U} \mathrm{SA}$ (group $\mathrm{A},-4.42 \pm 4.04^{\circ}$; group
$\mathrm{B},-1.15 \pm 3.64^{\circ} ; \mathrm{p}<0.05$ ), the $\Delta$ Post-OP GA (group A, $-2.91 \pm$ 9.56 ; group $\mathrm{B}, 0.52 \pm 9.84^{\circ} ; \mathrm{p}<0.05$ ), and the $\mathrm{F} / \mathrm{U} \mathrm{GA}$ (group $\mathrm{A}$, $13.11 \pm 10.35^{\circ}$; group B, 18.07 \pm 9.29 ; $\mathrm{p}=0.004$ ) (Table 6). Patients were then subdivided into the lordotic segmental angel change group and kyphotic SA change group by the $\Delta \mathrm{F} / \mathrm{U}$ SA equation. In Group A, 8 patients were assigned to the lordotic SA change group and 56 patients to the kyphotic segmental angel change group. In group B, 29 patients were assigned to the lordotic SA change and 40 patients to the kyphotic segmental angel change group. In the change of segmental cervical angle was statistically significant by the p-value less than 0.05 . In the change of global cervical angle, there was no sig- nificant difference $(\mathrm{p}=0.118)$ (Tables 7, 8).

\section{Fusion Rate, Fusion Time and Screw Fixation Type}

In mono-cortical fixation group, 61 patients represent complete graft consolidation. And, 3 patients occurs pseudoarthrosis.

Table 2. Segmental height, distraction, and subsidence of single-level anterior cervical discectomy and fusion

\begin{tabular}{lccc}
\hline \hline & Mono-cortical fixation group & Bi-cortical fixation group & p-value \\
\hline Pre-OP segmental height $(\mathrm{mm})^{*}$ & $37.559 \pm 3.41$ & $35.835 \pm 4.06$ & $0.009^{*}$ \\
Post-OP segmental height $(\mathrm{mm})^{*}$ & $40.996 \pm 3.45$ & $39.432 \pm 4.14$ & $0.020^{*}$ \\
F/U segmental height $(\mathrm{mm})$ & $37.050 \pm 3.35$ & $37.063 \pm 4.49$ & 0.983 \\
Distraction $(\mathrm{mm})$ & $3.436 \pm 1.52$ & $3.597 \pm 1.64$ & 0.561 \\
Subsidence $(\mathrm{mm})^{*}$ & $3.946 \pm 2.43$ & $2.369 \pm 1.96$ & $<0.001^{*}$ \\
\hline
\end{tabular}

OP: operative; F/U: follow-up.

*ndicates statistical significance.

Table 3. Relationship between significant subsidence and screw fixation

\begin{tabular}{lccc} 
& Non-significant subsidence & Significant subsidence & $\mathrm{p}$-value \\
\hline Mono-cortical screw fixation & 26 & 38 & $0.001^{*}$ \\
Bi-cortical screw fixation & 47 & 22 & \\
\hline
\end{tabular}

Indicates statistical significance.

Table 4. Subsidence and other surgical factors

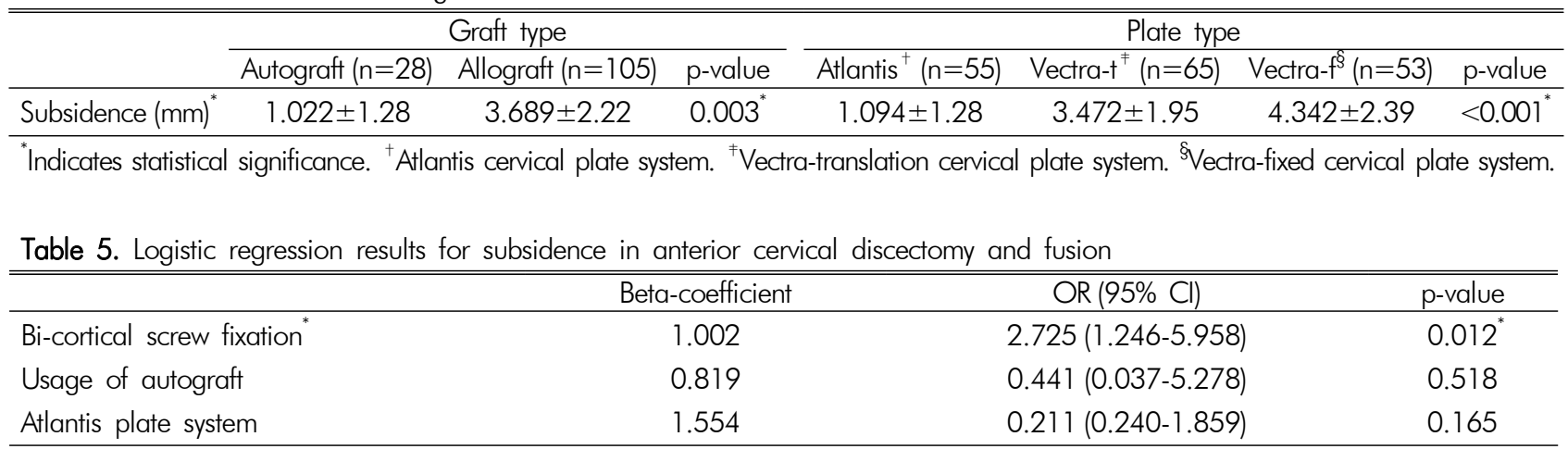

OR: odds ratio; $\mathrm{Cl}$ : confidence interval.

*Indicates the statistical significance. 
In bi-cortical fixation group 64 patients reveals complete graft consolidation. Five patients didn't achieved complete fusion. Fusion rate of mono-cortical fixation group was 95.3\%. And, in bi-cortical fixation group reveals $92.7 \%$ of fusion rate. In $\chi^{2}$ test, there was not significant difference between group ( $\mathrm{p}=$ 0.720 ). In fusion time, mono-cortical screw fixation group shows $8.29 \pm 3.15$ months. Bi-cortical screw fixation group achieve $7.75 \pm 2.56$ months. But, there was no significant difference in fusion time $(\mathrm{p}=0.295)$.

\section{DISCUSSION}

Graft subsidence is one of the major complications of ACDF, which can result in foraminal stenosis, segmental kyphosis, pseudarthrosis, and adjacent segment disease ${ }^{12)}$. The known risk factors of subsidence after ACDF are age, BMI, smoking history, low $\mathrm{BMD}^{2)}$, end plate preparation ${ }^{15)}$, cage type ${ }^{1,7,22)}$, location $^{21)}$, cervical alignment ${ }^{13,14)}$, and a small degree of segmental instability ${ }^{10,12,19,25)}$. Furthermore, Lee et al. ${ }^{14)}$ suggested that the main surgical and patient factors affecting subsidence are cervical alignment, age, and use of plates system. In this study, all operations were performed by a single surgeon, thus, biases derived from surgery such as end plate preparation and plate location are diminished. The variable factors that could result from surgery such as graft type and plate type were also included in this study. In this study, cervical plates were used in all patients and there was no significant difference in measurements of cervical alignment such Post-OP GA and Post-OP SA. In this study, bi-cortically fixed screw reveals less subsidence. Furthermore, in the logistic regression analysis, we confirmed that bi-cortically positioned screws was the main factor contributing to reduced subsidence $(p=0.012)$. These results could indicate evidence that bi-cortical screw fixation results in less subsidence than mono-cortical screw fixation in ACDF. According to an in vitro study, a small degree of segmental instability contributed to the development of subsidence $^{10)}$. Furthermore, bi-cortically positioned screw fixation has been reported to support additional stability more than mono-cortically positioned screw fixation ${ }^{3)}$. Thus, authors could confirm the hypothesis that bi-cortical screw fixation could provide more holding strength until the graft consolidation is achieved.

In recent study, which has been carried out by Wu et al. ${ }^{26)}$,

Table 6. Cervical alignment and screw fixation

\begin{tabular}{|c|c|c|c|}
\hline & Mono-cortical screw fixation group & Bi-cortical screw fixation group & p-value \\
\hline Pre-OP segmental angle $\left({ }^{\circ}\right)$ & $1.69 \pm 4.56$ & $1.60 \pm 5.52$ & 0.912 \\
\hline Post-OP segmental angle $\left({ }^{\circ}\right)$ & $6.57 \pm 4.35$ & $6.00 \pm 5.05$ & 0.500 \\
\hline F/U segmental angle ()$^{*}$ & $2.14 \pm 5.05$ & $4.84 \pm 4.83$ & $0.002^{*}$ \\
\hline Pre-OP global angle $\left(^{\circ}\right)$ & $14.08 \pm 9.38$ & $13.08 \pm 9.35$ & 0.567 \\
\hline Post-OP global angle $\left({ }^{\circ}\right)$ & $11.16 \pm 9.81$ & $13.60 \pm 9.35$ & 0.144 \\
\hline F/U global angle $\left({ }^{\circ}\right)^{*}$ & $13.11 \pm 10.35$ & $18.07 \pm 9.29$ & $0.004^{*}$ \\
\hline$\Delta$ Post-OP segmental angle $\left({ }^{\circ}\right)$ & $4.87 \pm 4.37$ & $4.40 \pm 4.88$ & 0.563 \\
\hline$\Delta \mathrm{F} / \mathrm{U}$ segmental angle $\left({ }^{\circ}\right)^{*}$ & $-4.42 \pm 4.04$ & $-1.15 \pm 3.64$ & $0.001^{*}$ \\
\hline$\Delta$ Post-OP global angle $\left({ }^{\circ}\right)^{*}$ & $-2.91 \pm 9.56$ & $0.52 \pm 9.84$ & $0.043^{*}$ \\
\hline$\Delta \mathrm{F} / \mathrm{U}$ global angle $\left(^{\circ}\right)$ & $1.94 \pm 9.25$ & $4.46 \pm 8.48$ & 0.104 \\
\hline
\end{tabular}

OP: operative; F/U: follow-up.

* Indicates statistical significance.

Table 7. Relationship between screw fixation and global cervical alignment

\begin{tabular}{lccc}
\hline & Global angle lordotic change group $(n=122)$ & Global angle kyphotic change group $(n=62)$ & $p$-value \\
\hline Mono-cortical fixation group & 56 & 8 & 0.118 \\
Bi-cortical fixation group & 66 & 3 & \\
\hline
\end{tabular}

Table 8. Relationship between screw fixation and segmental cervical alignment

\begin{tabular}{|c|c|c|c|}
\hline & $\begin{array}{l}\text { Segmental angle lordotic change group } \\
\qquad(\mathrm{n}=37)\end{array}$ & $\begin{array}{l}\text { Segmental angle kyphotic change group } \\
\qquad(n=96)\end{array}$ & p-value \\
\hline Mono-cortical fixation group & 8 & 56 & \multirow{2}{*}{$<0.01^{*}$} \\
\hline Bi-cortical fixation group & 29 & 40 & \\
\hline
\end{tabular}

Indicates the clinical significance. 
there was scarce evidence that subtle difference in subsidence contributes to directly favorable patient outcomes. However, considering the fact that severe complications can result from severe subsidence such as foraminal stenosis ${ }^{12)}$ or adjacent segment disease $e^{1,7,22,26)}$. Surgeons should not neglect the subsidence. Furthermore, surgeons should find a way to maintain the distance of the intervertebral space. Although there is the potential danger of neuronal and vascular injury of the central nervous system through penetration of the anterior aspect of the dura matter or cervical spinal cord, bi-cortical screw fixation has the potential benefit of stabilizing the cervical segment and protecting against graft subsidence. Thus, this safe surgical modality should be secured.

Interestingly, although both the Atlantis plate system and Vectra plate system are self-locking plate systems, Atlantis selflocking systems have superior data regarding subsidence. When the subsidence in the Atlantis plate system group and Vectra plate system group was compared, a significant difference in subsidence was found. Therefore, we could derive the hypothesis that the locking system of the Atlantis cervical plate provides more holding strength than that of the Vectra cervical plate system.

In this study, use of autograft and the Atlantis cervical plate system contributed to less subsidence in ACDF patients. According to this study, iliac bone graft might be the best option to minimize subsidence. However, there are several limitations, such as harvesting site pain, hematoma, fracture, and meralgia paresthetica $^{11)}$. To reduce these complications, multivariate allografts were introduced, such as polyetheretherketone, titanium, and polymethyl methacrylate ${ }^{18)}$. In future studies, proper allografts that are as strong as the iliac bone graft should be introduced in ACDF.

Known factors that influence cervical alignment after ACDF include preoperative alignment ${ }^{18)}$, intraoperative segmental distraction $^{7)}$, surgical level (single or multiple), and graft characteristics $^{22)}$. In this study, when including these surgical factors, no significant differences in demographic data were observed. There was no significant difference in Pre-OP SA or Post-OP SA between 2 groups $(\mathrm{p}=0.912, \mathrm{p}=0.500)$. And also, in distraction, statistical differences weren't observed between 2 groups ( $\mathrm{p}=0.561$ ). But $\mathrm{F} / \mathrm{U}$ SA and $\Delta \mathrm{F} / \mathrm{U}$ SA were significant difference between 2 groups ( $\mathrm{p}=0.002, \mathrm{p}=0.001$ ). In $\Delta \mathrm{F} / \mathrm{U}$ SA, bi-cortical screw fixation group shows less value than mono-cortical screw fixation group (group A, $-4.42 \pm 4.04^{\circ}$; group B, $-1.15 \pm 3.64^{\circ} ; \mathrm{p}<$ 0.05 ). As a result, Bi-cortical screw fixation group reveals less kyphotic SA change than mono-cortical fixation group. According to Lee et al. ${ }^{12)}$, postoperative subsidence unexpected kyphotic changes in cervical alignment. And, bi-cortical screw fixation group reveals less subsidence in this study. We could make the hypothesis that bi-cortical screw fixation contribute make less kyphotic deformation by making less subsidence. Thus, bi-cortical screw fixation has potential advantage in maintaining SA than mono-cortical screw fixation.
According to Gillis et al. ${ }^{8}$, an improvement in focal lordosis was significantly correlated with an improvement in overall lordosis. A recent study reported that cervical lordosis may be more important for the long-term clinical outcome ${ }^{14)}$. Thus, we hypothesize that bi-cortical screw fixation in ACDF has the potential advantage to maintain lordotic cervical alignment resulting in a more favorable outcome. Furthermore, according to Chung et al. ${ }^{4}$, kyphotic deformation is associated with development of adjacent segment disease. And, consider the result that bi-cortical screw fixation group reveals less kyphotic deformation than mono-cortical fixation group. Thus, this type of screw insertion technique could contribute to long term favorable outcome in patient who undergoes ACDF. As a result, Bi-cortical screw fixation in ACDF could have the potential advantage in creating a favorable environment by maintaining intervertebral space and local lordosis of affected level.

In this study, total 69 cases were inserted screw as bi-cortically. And, there was no immediate spinal cord injury or dura mata injuries. And also, bone bleeding complications didn't observed. Thus, inserting bi-cortical screws as $1 \mathrm{~mm}+\mathrm{AP}$ diameter could be suggest as safe surgical technique in single level ACDF.

This study has some limitations. First, patient characteristics considered to contribute to graft subsidence, such as BMI, $\mathrm{BMD}$, and smoking history were not excluded. Thus, non-surgical factors could be the main contributing factors for subsidence or kyphotic cervical angle change. Second, the type of screw used, that is, variable angled or fixed angled screw, was not considered. Variable screws and fixed type screws have different effects in terms of graft stability; therefore, screw type could affect subsidence or the change in the cervical angle. Further study should be conducted that counts the types of screws in ACDF cases. Third, we did not determine the insertion angle of the screws. Considering the physics of the anterior cervical plate system acting as a cantilever beam in ACDF cases, the insertion angle could create a bias in cervical angle change. Thus, those factors could be act as bias in this study. Fourth, we didn't analyze the clinical outcome or complications in this study. Fortunately, we didn't experience major complications such as iatrogenic spinal cord injury or dural injuries. But, long-tern clinical outcomes should be secured. Fifth, we didn't analyzed the change of screw length or change of screw angulation. Considering the fact that ACDF screws have went through dynamic change in cervical spine. Those dynamic changes have the risk of progressing cord compression by screw depth change or screw angle change. Thus, to prove the validity of bi-cortical screw fixation in ACDF, further studies that include the insertion angle of the screw or angle change of screw should be planned. And also, dynamic change of screw inserted depth should be conducted. Finally, this study was designed as a retrospective study; thus, more randomized studies or metaanalysis should be conducted to verify the usefulness of bicortical screw fixation in ACDF. 


\section{CONCLUSION}

The bi-cortically positioned screw fixation system was found to contribute towards reduced graft subsidence and a more lordotic SA change in single-level ACDF cases.

\section{CONFLICTS OF INTEREST}

No potential conflict of interest relevant to this article was reported.

\section{REFERENCES}

1. Bartels RH, Donk RD, Feuth T: Subsidence of stand-alone cervical carbon fiber cages. Neurosurgery 58:502-508, 2006

2. Brenke C, Dostal M, Scharf J, Weiß C, Schmieder K, Barth M: Influence of cervical bone mineral density on cage subsidence in patients following stand-alone anterior cervical discectomy and fusion. Eur Spine J 24:2832-2840, 2015

3. Chen IH: Biomechanical evaluation of subcortical versus bicortical screw purchase in anterior cervical plating. Acta Neurochir (Wien) 138:167-173, 1996

4. Chung JY, Park JB, Seo HY, Kim SK: Adjacent segment pathology after anterior cervical fusion. Asian Spine J 10:582-592, 2016

5. Conrad BP, Cordista AG, Horodyski M, Rechtine GR: Biomechanical evaluation of the pullout strength of cervical screws. J Spinal Disord Tech 18:506-510, 2005

6. Elder BD, Sankey EW, Theodros D, Bydon M, Goodwin CR, Lo SF, et al.: Successful anterior fusion following posterior cervical fusion for revision of anterior cervical discectomy and fusion pseudarthrosis. J Clin Neurosci 24:57-62, 2016

7. Gercek E, Arlet V, Delisle J, Marchesi D: Subsidence of standalone cervical cages in anterior interbody fusion: warning. Eur Spine J 12:513-516, 2003

8. Gillis CC, Kaszuba MC, Traynelis VC: Cervical radiographic parameters in 1- and 2-level anterior cervical discectomy and fusion. J Neurosurg Spine 25:421-429, 2016

9. Karikari IO, Jain D, Owens TR, Gottfried O, Hodges TR, Nimjee $\mathrm{SM}$, et al.: Impact of subsidence on clinical outcomes and radiographic fusion rates in anterior cervical discectomy and fusion: a systematic review. J Spinal Disord Tech 27:1-10, 2014

10. Kettler A, Wilke HJ, Claes L: Effects of neck movements on stability and subsidence in cervical interbody fusion: an in vitro study. J Neurosurg 94:97-107, 2001

11. Kim DR, Moon BG, Kim JH, Kang HI, Lee SJ, Kim JS: Subsidence ratio after anterior cervical interbody fusion using an intraoperative custom-made cervical cage. J Korean Neurosurg Soc 41:301-305, 2007

12. Lee SH, Lee JS, Sung SK, Son DW, Lee SW, Song GS: The effect of uncinate process resection on subsidence following an- terior cervical discectomy and fusion. J Korean Neurosurg Soc 60:550-559, 2017

13. Lee SH, Lee JS, Sung SK, Son DW, Lee SW, Song GS: A lower $\mathrm{T} 1$ slope as a predictor of subsidence in anterior cervical discectomy and fusion with stand-alone cages. J Korean Neurosurg Soc 60:567-576, 2017

14. Lee YS, Kim YB, Park SW: Risk factors for postoperative subsidence of single-level anterior cervical discectomy and fusion: the significance of the preoperative cervical alignment. Spine (Phila Pa 1976) 39:1280-1287, 2014

15. Lim TH, Kwon H, Jeon CH, Kim JG, Sokolowski M, Natarajan $\mathrm{R}$, et al.: Effect of endplate conditions and bone mineral density on the compressive strength of the graft-endplate interface in anterior cervical spine fusion. Spine (Phila Pa 1976) 26:951-956, 2001

16. Lowery GL, McDonough RF: The significance of hardware failure in anterior cervical plate fixation. Patients with 2- to 7-year follow-up. Spine (Phila Pa 1976) 23:181-186, 1998

17. Ning X, Wen Y, Xiao-Jian Y, Bin N, De-Yu C, Jian-Ru X, et al.: Anterior cervical locking plate-related complications; prevention and treatment recommendations. Int Orthop 32:649-655, 2008

18. Noordhoek I, Koning MT, Jacobs WCH, Vleggeert-Lankamp CLA: Incidence and clinical relevance of cage subsidence in anterior cervical discectomy and fusion: a systematic review. Acta Neurochir (Wien) 160:873-880, 2018

19. Olivares-Navarrete R, Gittens RA, Schneider JM, Hyzy SL, Haithcock DA, Ullrich PF, et al.: Osteoblasts exhibit a more differentiated phenotype and increased bone morphogenetic protein production on titanium alloy substrates than on poly-ether- etherketone. Spine J 12:265-272, 2012

20. Ordway NR, Rim BC, Tan R, Hickman R, Fayyazi AH: Anterior cervical interbody constructs: effect of a repetitive compressive force on the endplate. J Orthop Res 30:587-592, 2012

21. Park JY, Choi KY, Moon BJ, Hur H, Jang JW, Lee JK: Subsidence after single-level anterior cervical fusion with a standalone cage. J Clin Neurosci 33:83-88, 2016

22. Schmieder K, Wolzik-Grossmann M, Pechlivanis I, Engelhardt M, Scholz M, Harders A: Subsidence of the wing titanium cage after anterior cervical interbody fusion: 2-year follow-up study. J Neurosurg Spine 4:447-453, 2006

23. Smith GA, Pace J, Corriveau M, Lee S, Mroz TE, Nassr A, et al.: Incidence and outcomes of acute implant extrusion following anterior cervical spine surgery. Global Spine J 7:40S-45S, 2017

24. Smith GW, Robinson RA: The treatment of certain cervicalspine disorders by anterior removal of the intervertebral disc and interbody fusion. J Bone Joint Surg Am 40A:607-624, 1958

25. Wu SH, Li Y, Zhang YQ, Li XK, Yuan CF, Hao YL, et al.: Porous titanium- 6 aluminum-4 vanadium cage has better osseoin tegration and less micromotion than a poly-ether-ether-ketone cage in sheep vertebral fusion. Artif Organs 37:E191-E201, 2013

26. Wu WJ, Jiang LS, Liang Y, Dai LY: Cage subsidence does not, but cervical lordosis improvement does affect the long-term results of anterior cervical fusion with stand-alone cage for degenerative cervical disc disease: a retrospective study. Eur Spine J 21:1374-1382, 2012 